\title{
De damas da noite a vovós do sexo: referenciação da prostituta idosa na mídia
}

\author{
From "night ladies" to "sex grannies": the referencing process of the "elderly \\ prostitute" in the media
}

Romilda Meira de Souza Barbosa ${ }^{1}$

Universidade Federal de Mato Grosso do Sul

Celina Aparecida Garcia de Souza Nascimento

Universidade Federal de Mato Grosso do Sul

\begin{abstract}
- RESUMO: Neste trabalho, examinamos o processo de referenciação da "prostituta idosa" em manchetes da reportagem Damas da Noite, produzidas no período anterior e posterior à exibição da matéria no Programa Repórter Record Investigação. Adotamos a concepção sociointeracionista de texto, como espaço discursivo, onde ocorrem processos para progressão textual e orientação argumentativa. Nesta perspectiva, a designação do objeto de discurso passa a ser uma atividade sociocognitiva, resultante da negociação entre interlocutores (sujeitos sociais) no uso da língua, segundo preconizam os teóricos Marcuschi e Koch $(2002)$ Koch $(2005,2008,2010)$ e Cavalcante (2005). Observamos que, dentre as estratégias de referenciação selecionadas pelo produtor textual, destacam-se as expressões nominais anafóricas, que não apenas recategorizam o objeto, mas promovem a progressão textual e argumentativa. Na proposta argumentativa do locutor, a expressão nominal "As Damas da noite" faz remissão às prostitutas do passado, de status social e financeiro, no auge da atividade, enquanto que "as vovós do sexo" designam tais "damas", agora, idosas, para quem a produção no mercado do sexo entrou em decadência.
\end{abstract}

- PALAVRAS-CHAVE: Prostituição. Idosas. Anáfora. Nominalização.

- ABSTRACT: In this work we examine the referencing process of the "elderly prostitute" in Damas da Noite (night ladies) headline reports produced in the anterior and posterior period exhibition of the theme on the Programa Repórter Record Investigação (Investigation Reporter Program - Record TV Show). We adopt the sociointeractionist conception of text, as a discursive space, where processes for textual progression and argumentative orientation occur. In this perspective, the discourse object designation becomes a sociocognitive activity resulted from the negotiation between interlocutors (social subjetcs) in the language use, according to Marcuschi \& Koch (2002), Koch (2005, 2008, 2010) and Cavalcante (2005). Among the referencing strategies selected by the textual producer, we observe the anaphoric nominal expressions stand out, which not only recategorize the object, but promote the textual and argumentative progression. In the locutor argumentative proposal the nominal expression As Damas da noite (night ladies) it makes remission to the prostitutes of the past with high social and financial status activity while the "sex grandmas" designate such "ladies," now elderly, for whom production in the sex market has failed.

- KEYWORDS: Prostitution. Elderly women. Anaphora. Nominalization.

\footnotetext{
${ }^{1}$ Mestre em Letras pela UFMS. Doutoranda em Letras (UFMS/Três Lagoas - MS. ro1000dameira@gmail.com

${ }^{2}$ Doutora em Linguística e Língua Portuguesa pela UNESP/Araraquara. Docente da Universidade Federal de Mato Grosso do Sul (UFMS). Docente do Programa de Pós-Graduação em Letras da UFMS/Três Lagoas-MS. celinaufms@hotmail.com
} 


\section{Considerações iniciais}

$\mathrm{Na}$ esteira da interpretação de práticas discursivas da prostituição, buscamos observar os modos de designação da prostituta idosa em textos veiculados durante o período de divulgação e exibição da reportagem "Damas da Noite" pelo semanário televisivo Repórter Record Investigação.

Selecionamos seis manchetes no Portal R7, canal digital da Tevê Record mesma emissora do programa - e examinamos processos de referenciação, de acordo com as teorias de Marcuschi e Koch (2002), Koch (2005, 2008, 2010) e Cavalcante (2005). Investigamos a recategorização do objeto de discurso e sua relação com a construção de sentidos do texto, na perspectiva sociointeracionista da Linguística Textual, em que texto resulta de um trabalho discursivo, intersubjetivo e sociocognitivo dos sujeitos. Queremos destacar que este texto resulta da conclusão da disciplina Tópicos Especiais: Processos Constitutivos da Referenciação, no Programa de PósGraduação Doutorado em Letras, área de Estudos Linguísticos - UFMS.

Observamos que dentre as estratégias escolhidas pelo produtor textual, sobressai-se a nominalização anafórica que, ao recategorizar o objeto, sob diversas formas, contribui para a progressão e avaliação argumentativa e à multiplicidade de sentidos.

\section{Aporte teórico}

O conceito clássico de referência como algo estático, termo a termo, não se sustenta desde que a questão ocupou grande espaço nos debates teóricos de linguistas e filósofos da linguagem, o que resultou em deslocamentos em sua construção teórica. Referência passou a ser entendida como exterior à língua, mas inscrita no discurso. Ela não é a realidade, mas o que o discurso institui como real. A relação entre língua e realidade é histórica e dinâmica, conforme postula Cardoso (2003).

Referência trata "daquilo que designamos, representamos, sugerimos quando usamos um termo ou criamos uma situação discursiva referencial com essa finalidade", (MARCUSCHI e KOCH, 2002, p.37). Percebemos a existência de um fenômeno, no qual o que é designado se dá como "objeto de discurso", pois ao designar, o sujeito fica condicionado a imposições co e contextuais, da ordem cultural, social, histórica e do próprio processamento da língua. Nesta perspectiva, os autores postularam que referência é preterida a referenciação para denominar tal processo.

Processos de referenciação são conjuntos de estratégias utilizadas pelo locutor, dentre elas, as anáforas sem antecedente explícito e as anáforas realizadas por expressões nominais definidas, conforme delimitaram Marcuschi e Koch (2002). Estratégias responsáveis pela orientação referencial, que é dinâmica, de forma que referir é diferente de remeter e de retomar. A progressão do texto geralmente ocorre por um tipo de remissão, neste caso, destaca-se a anáfora, que é uma estratégia de textualização não linear, mas sobremaneira fundamental para a coerência discursiva porque é quem confere estabilidade ao texto.

Marcuschi e Koch (2002) postulam que no quadro da referenciação, anáforas podem ser retomadas correferenciais recategorizadoras não-co-significativas porque mesmo o referente estando no cotexto, ao ser retomado, seu sentido pode não ser o mesmo. Quando se trata de anáfora nominal, esta deve ser constituída "minimamente de um determinante definido seguido de um nome" e essa forma de designação se distingue em descrições definidas e nominalizações, ambas em processamento por meio 
de sintagma nominal. No caso desta última, o substantivo predicativo é nome-núcleo da construção.

O emprego da anáfora nominal representa uma seleção do produtor do texto, dentre as propriedades que caracterizam o objeto, conforme seu projeto comunicativo. "Trata-se da ativação, dentre os conhecimentos pressupostos como partilhados com o interlocutor, de características ou traços do referente que o locutor procura ressaltar ou enfatizar" (Idem, 2002, p. 45). Por este aspecto, o objeto de discurso pode ser recategorizado de diversas formas, e a escolha de um determinado objeto é carregada de valores e posicionamentos.

Ainda neste aporte teórico, Cavalcante (2005) defende que, ao elegermos como critério primário a retomada de referentes no discurso, podemos visualizar uma interseção entre dêixis, anáfora e introdução referencial, o que leva a uma soma de conhecimentos e construção de sentidos. As três estratégias se superpõem, mas não se excluem.

Cavalcante (2005) reitera que a referenciação é um trabalho sociocognitivo, resultante da negociação entre interlocutores, e, para exemplificar, examina o poema Rosa de Hiroshima, (CAVALCANTE, 2005, p. 125-126), em que a introdução referencial, embora feita no título é também uma anáfora recategorizadora porque seu referente "Hiroshima" é perceptível no entorno contextual. Assim, destaca que a recategorização ocorre mesmo quando o objeto de discurso não está linguisticamente marcado, visto que pode ser retomado com base no conhecimento prévio e de mundo dos interlocutores.

Processo complexo, dada a própria complexidade da língua, que é ação e não um produto, na referenciação, os objetos de discurso estão em contínuo contato com o contexto, implicando uma dinamicidade semântica da língua, de modo a se produzirem linguisticamente. Logo, tudo que o falante julga adequado na produção referencial se faz por meio do processo de "acessibilidade mental do interlocutor", dos arquivos cristalizados em sua memória, com base em seu contexto cultural partilhado, no discurso e na situação de fala.

\section{Das condições de produção: em cena, o texto midiático}

A produção discursiva ocorre em circunstâncias específicas, considerando-se interlocutores, o espaço de veiculação dos textos, função e objetivo do produtor. Por este aspecto, apresentamos, mesmo que de forma breve, o contexto situacional de produção: o espaço midiático onde veicularam os textos analisados.

Entendemos mídias como suportes que integram comunicação e informação seguindo diversas lógicas, dentre elas, a econômica, que interfere diretamente na sua produção informacional, visto que se trata de empresas da comunicação impressa, digital e televisiva, conforme preconiza Charaudeau (2006). Os contextos de produção e recepção na mídia são "produzidos", logo, o evento midiático orienta efeitos de sentidos que levem ao alcance de suas lógicas e de seu público-alvo. O público interpreta as mensagens de acordo com suas condições de recepção do produto midiático, mas orientado argumentativamente pela rede de estratégias que a mídia tece com vistas a evidenciar características do evento segundo a forma como ela o vê, de modo a orientar os efeitos de sentidos.

Neste quadro, analisamos seis manchetes veiculadas no Portal R7, da emissora Record de Televisão, durante o período que antecedeu e sucedeu a apresentação da reportagem Damas da Noite pelo semanário Repórter Record Investigação, exibido na última semana de março de 2015. 
Escolhemos as manchetes, "notícias de destaque", por entendermos que estas, dentre as demais contidas na edição do texto midiático, constituem textos cuja função conativa objetiva influenciar e convencer o interlocutor, o que torna mais evidente a orientação avaliativa do produtor textual em sua escolha de termos para a designação do objeto de discurso neste contexto de produção e recepção de seu discurso.

Como as manchetes trataram da publicidade do programa em questão, convém contextualizar o Repórter Record Investigação, um semanário veiculado pela TV Record desde a década de 1990 que passou por diversas reformulações para a emissora conciliar sua grade de programação, mas em 2009 se consolidou como programa investigativo, o que lhe rendeu mudança também no nome. Sob o comando do jornalista Domingos Meirelles, trata de assuntos polêmicos para "desvendar temas de interesse público".

O Programa tem ethos de suposta exclusividade, daí enunciações solenes, observada em construções sintáticas e lexicais na divulgação das matérias, como verificamos nos enunciados: "Programa exibe reportagem exclusiva sobre as vovós do sexo", ou em "Pela primeira vez na televisão brasileira, o programa mostra as transformações no mercado sexual". O conceito de ethos discursivo é acionado por Maingueneau (2004) para evocar a ligação estreita entre um discurso e seu modo de enunciação. O sentido propiciado pelo discurso impõe-se tanto pelo ethos como pelas "ideias" que transmite, as quais se apresentam por uma maneira de dizer.

\section{De damas da noite a vovós do sexo: recategorização da prostituta idosa}

No corpus, selecionamos as expressões mais significativas por trazerem em seus contextos acréscimos de informações ou ajustes, a saber:

(1) 26/03/2015 ÀS 18H27 - Programa exibe reportagem exclusiva sobre as "vovós do sexo" na cidade de Santos. Programa é exibido às segundas, às 22h30, com apresentação de Domingos Meirelles. ${ }^{3}$

(2) 26/03/2015 20H15 - Repórter Record Investigação revela quem são as vovós do sexo ${ }^{4}$

(3) 30/03/2015 às 13h19 - Damas da Noite: do glamour dos cabarés à decadência da prostituição na rua. Veja quem são as profissionais do sexo vítimas de uma doença silenciosa nesta segunda-feira (30), às $22 \mathrm{~h} 30$, no Repórter Record Investigação.

$\mathrm{O}$ Repórter Record Investigação da segunda-feira (30), às 22h30, exibe reportagem exclusiva com mulheres que possuem mais de meio século de vida e que continuam a despertar o desejo e a fantasia de muitos admiradores. ${ }^{5}$

(4) $30 / 03 / 2015$ às $22 \mathrm{~h} 29$ - Confira os bastidores da reportagem sobre as "vovós do sexo" da zona portuária de Santos. O repórter Lucio Sturm e editor Marcelo Magalhães contam os bastidores da reportagem "Damas da Noite", que mostrou como vivem mulheres com mais de 50 anos que se prostituem na zona portuária de Santos. Confira! ${ }^{6}$

\footnotetext{
3 Disponível em: <http://noticias.r7.com/reporter-record-investigacao/programa-exibe-reportagem-exclusiva-sobreas-vovos-do-sexo-na-cidade-de-santos-27032015>. Acesso em jul. 2015.

4 Disponível em: <http://noticias.r7.com/reporter-record-investigacao/videos/reporter-record-investigacao-revelaquem-sao-as-vovos-do-sexo-16102015>. Acesso em set. 2017.

Disponível em: <http://noticias.r7.com/reporter-record-investigacao/videos/damas-da-noite-do-glamour-doscabares-a-decadencia-da-prostituicao-na-rua-30032015>. Acesso em mai.2015.

6 Disponível em: <http://rederecord.r7.com/video/confira-os-bastidores-da-reportagem-sobre-as-vovos-do-sexo-dazona-portuaria-de-santos-5519d50d0cf2d5548cf78b91/> Acesso em jul.2015.
} 
(5) $30 / 03 / 2015$ às $22 \mathrm{~h} 30$ - Acompanhe agora no \#RepórterRecordInvestigação como trabalham as "vovós do sexo" em Santos (SP)

(6) Publicado em 5 de abr de 2015 - O Repórter Record Investigação: como vivem as idosas que ainda se prostituem [30/03/2015]. ${ }^{8}$

A estreia do referente no texto ocorre em (1) pela expressão nominal "as vovós do sexo". A introdução referencial e anáfora se superpõem quando o referente pode ser encontrado fora do cotexto, o que nos leva a entender que tal "introdução referencial", (CAVALCANTI, 2005, p.129-30), seja também uma anáfora nominal recategorizadora do objeto não-correferenciado no texto, que são "As damas da noite" - título da reportagem, que sequer havia ido ao ar nesta cena enunciativa, mas que compunha o conhecimento prévio do produtor textual.

Entendemos ainda que, mesmo a expressão nominal "As damas da noite" embora não esteja correferenciada em 1 e 2, pode ser uma remissão ao objeto, pode se tratar de uma anáfora recategorizadora do referente "prostituta idosa", porque é perceptível pelo entorno discursivo, pela memória, pelo conhecimento sócio-histório e de mundo dos interlocutores. "Dama da noite" designou prostituta no passado, mas a expressão entrou em desuso. Não se denomina prostituta contemporânea dessa forma. Há novas designações, como "garota de programa", "massagista", "acompanhante", "promoter" já cristalizadas no espaço midiático para referirem os sujeitos da prostituição, segundo Barbosa (2008).

Ainda nesta perspectiva de análise sociointeracionista da linguagem, intentamos mostrar que na construção do objeto de discurso o produtor seleciona as formas linguísticas correspondentes a seu projeto de dizer, mas tal seleção é feita por um sujeito ao mesmo tempo singular e social, logo, ele pode rejeitar e assumir diversos valores sociais simultaneamente.

Assim, seus textos veiculam fragmentos de outros, cujo dinamismo ativará no sujeito-leitor a construção do sentido através do "trabalho incessante com o já-dito", uma vez que "a língua não existe fora dos sujeitos sociais que a falam e fora dos eventos discursivos nos quais intervêm e nos quais mobilizam seus saberes", (KOCH, 2009, p.44). Por este aspecto, há um percurso interativo de construção argumentativa socialmente organizada no texto, tal como podemos verificar neste recorte dos enunciados:

(1) as "vovós do sexo"

(2) as vovós do sexo

(3) Damas da Noite

as profissionais do sexo vítimas de uma doença silenciosa

mulheres que possuem mais de meio século de vida

(4) as "vovós do sexo"

"Damas da Noite"

mulheres com mais de 50 anos que se prostituem na zona portuária de Santos. as "vovós do sexo"

(6) as idosas que ainda se prostituem.

Tratam-se de anáforas nominais, que desempenham papel decisivo neste processo de construção e recategorização do objeto de discurso, segundo Koch (2008). Neste texto, ocupam a mesma função argumentativa das definições e das descrições. $\mathrm{O}$

\footnotetext{
${ }^{7}$ Disponível em: $<$ https://twitter.com/tvrecord/status/582716684693348352>. Acesso em julho/2015.

${ }^{8}$ Disponível em: $<$ https://www.youtube.com/watch?v=0XkIkC1G9pU>. Acesso em julho/2015.
} 
nome-núcleo vem acompanhado de modificadores, que ora definem, como observamos em "Damas da Noite", "profissionais do sexo", "vovós do sexo", ora descrevem, como se vê nas adjetivas: "idosas que ainda se prostituem", e "mulheres com mais de 50 anos que se prostituem". Nestas formas de referenciação, a ênfase está na caracterização do objeto, uma vez que o emprego de "descrição definida implica uma escolha do locutor dentre as propriedades ou qualidades capazes de caracterizar o referente", (MARCUSCHI e KOCH, 2002, p.40).

Os termos são todos posteriores ao nome-núcleo do sintagma - Damas, profissionais, vovós, mulheres, idosas -, acompanhando-o como decisivos na orientação argumentativa, visto que qualificam, caracterizam ou determinam o nome e colaboram na construção do objeto de discurso, estabelecendo, assim, uma relação estreita e significativa entre a referenciação e a argumentação.

Esta estratégia de referenciação leva à recategorização lexical por meio de novas designações, como: damas, profissionais, vovós, mulheres, idosas, no entanto, são os modificadores nestas expressões nominais que "reforçam" o objeto de discurso e indicam o ponto de vista de quem enuncia. Noutros, termos, trata-se de anáforas nominais que remetem e recategorizam lexicalmente o objeto de discurso "prostituta idosa" e trazem o aporte de uma informação nova que leva a uma reinterpretação do precedente (damas, profissionais, vovós, mulheres, idosas) cada qual também modificado por expressões definidas (da noite, do sexo) descrições definidas: "com mais de 50 anos", "vítimas de uma doença silenciosa" marcando a representação cognitiva da realidade compartilhada socialmente pelos interlocutores.

Observamos ainda as expressões anafóricas nominais por meio de paráfrases, cuja função é elaborar definições em relação ao objeto de discurso anteriormente introduzido, no caso o referente da introdução referencial: "as vovós do sexo", recategorizado, como observamos em:

(3) as profissionais do sexo vítimas de uma doença silenciosa mulheres que possuem mais de meio século de vida mulheres com mais de 50 anos que se prostituem na zona portuária de Santos. (6) as idosas que ainda se prostituem

Nesta proposta argumentativa do enunciador, o referente textual é (re)ativado de maneira recorrente ainda por relações anafóricas correferenciais (porque se trata do mesmo referente presente no cotexto), recategorizadoras (porque promove a alteração referencial) não-co-significativas (porque provocam mudança semântica). É o que se pode verificar nestas retomadas correferenciais por anáforas nominais sob a forma de paráfrases que, mesmo quando a função é caracterizar ou ressaltar o objeto de discurso, levam à sua recategorização, segundo postularam Marcuschi e Koch (2002).

E por fim, verificamos a nominalização metafórica. Salientamos que no contexto de organização do texto, em que o locutor trilha por caminhos não-lineares organizando enunciados por meio de suas escolhas lexicais, a metáfora se apresenta como uma dessas possibilidades de seleção. Seu valor argumentativo se constitui na introdução e retomada do referente no texto, quando se torna uma maneira diferente de perceber o objeto a partir de recortes ou posições assumidas pelos interlocutores.

Para compreensão da metáfora, é fundamental considerar o entorno sóciohistórico e ideológico organizado na memória dos interlocutores. A metáfora, embora esteja presente na língua, só pode ser interpretada além das palavras, na organização discursiva, na nossa forma de percepção e interpretação do mundo. Vejamos as metáforas: 
Interpretamos que o teor argumentativo nestas expressões nominais metafóricas conduz a uma reflexão semântica acerca do referente, pois a escolha da metáfora para a recategorização do referente é importante para realizar uma avaliação que permita estabelecer a orientação argumentativa do texto, de acordo com Koch (2005).

Historicamente, o lexema "dama" designou "mulher de fino trato", mas foi (re)significado quando passou referir-se a "prostituta", num processo de retomadas de referentes, dentre os quais podemos citar a "cortesã", da Itália Renascentista - mulher cuja beleza e educação a qualificava a representar a elite das prostitutas porque atendia às necessidades sexuais e sociais dos aristocratas. Ainda nesta perspectiva, conforme a historiadora Roberts (1998) por esse protótipo de prostituta, bela e educada, que exigia preços elevados, resgatava-se o prestígio da "hetairae" grega, que mesmo com semelhantes atributos, diferia no caráter místico de sua atividade: era a conselheira do nobre e o acompanhava em suas atividades políticas, ao passo que a atividade da cortesã era "puramente secular" no sentido de serem préstimos sexuais, (ROBERTS, 1998, p.128-35).

A designação de prostituta como "dama" teve seu "ápice" nas décadas de 195070, contexto em que o escoamento da produção cafeeira no país teve seu apogeu na zona portuária de Santos. Havia ali pessoas de todos os continentes, ávidas por uma relação familiarizada após longo período de navegação. Concomitantemente, no auge de sucesso estiveram "as damas da noite", prostitutas que desfrutavam certo status e ascensão financeira por serem preferidas de um público consumidor abastado financeiramente, composto de boêmios, poetas, chefes de estado.

Como exemplos, podemos citar a dama Hilda Furacão, que nos anos 1950 e 1960 movimentou o comércio do sexo na alta sociedade de Minas Gerais e cuja trajetória inspirou livro e minissérie da Tevê Globo, e Eny Cezarino, da alta sociedade paulistana que também teve sua biografia editada, cuja história se transformou em minissérie $A$ dama da noite pela mesma emissora de televisão. Neste sentido, tratam-se de prostitutas cujo diferencial fora criar um ambiente meio "familiar", de mulher comportada, bem penteada, perfumada - referência sobre como se vestir, segurar o cigarro, como sentar - artistas, profissionais - que se apresentavam e atendiam nos cafés e bares noturnos, não nas ruas.

Há mais de meio século na atividade, tais damas envelheceram e igualmente o termo que as designava entrou em desuso. Estas mesmas "damas da noite" que no auge da juventude entraram no mercado do sexo e passaram a desenvolver apenas a atividade de venda de sedução, hoje, idosas, passaram a ser designadas "as vovós do sexo", na mídia.

Neste quadro, entendemos que as expressões nominais metafóricas "as damas da noite" e "as vovós do sexo" são recategorizações do objeto de discurso "prostitutas idosas". Abrimos parênteses para destacar que, considerando o conhecimento prévio e de mundo dos interlocutores, a nominalização "as vovós" pode fazer remissão a "idosas", mas não podemos dizer que tal nome tenha o mesmo efeito de sentido possível no discurso da Lei, pelo Estatuto do Idoso, quando "idosas" designam "pessoas com idade igual ou superior a 60 (sessenta) anos".

Isso porque, se considerarmos que na indústria do sexo, a idade é determinante, a prostituta que tiver passado dos 30 anos começa a sofrer desvalorização em termos mercadológicos, o que seria outra discussão. Neste caso, "vovós" fazem remissão a "prostituta" que envelheceu, para quem o mercado também ficou decadente, mas 
continua na ativa, com disposição, carisma - segundo o ideário de vovó no senso comum, de senhoras experientes, carismáticas, bondosas e atenciosas.

\section{Considerações finais}

No processamento do texto, o locutor acionou um conjunto de estratégias de referenciação do objeto de discurso a partir de propriedades determinadas pelo contexto ou no co-texto, atribuídas por ele, conforme seus propósitos de influenciar o interlocutor. Usou o processo da nominalização e promoveu a recategorização da "prostituta idosa" de Santos, no início, como "as Damas da noite" que desfrutaram de status social e financeiro no auge da atividade na juventude. Entanto, a experiência não as manteve neste posto, nem mesmo na forma de designação, a ponto de serem designadas "as vovós do sexo", para quem o mercado tornou-se igualmente improdutivo.

No quadro das estratégias utilizadas pelo enunciador textual para a referenciação, encontram-se anáforas nominais recategorizadoras por meio de metáforas, paráfrases expressões nominais e descrições definidas, onde os modificadores, tais como: "da noite" e "do sexo", relativos à prostituta são responsáveis pela especificação do objeto de discurso e representam um tipo de escolha que privilegia a função, não o nome.

Feitas estas considerações, concluímos que a atividade processual de recategorização se fez pelo viés da nominalização, no escopo teórico da referenciação como atividade discursiva mediada pela intersubjetividade dos interlocutores, cujas escolhas lexicais orientam-se pela dinâmica pragmático-cognitiva, com incursões pelas condições de produção e recepção, como sintetizamos no quadro1 - Processos de Referenciação:

\begin{tabular}{|c|c|c|c|c|c|c|c|c|}
\hline & & & QUADRO & 1 - PROCESS & OS DE REF & FERENCIAÇÃO & & \\
\hline \multirow{10}{*}{ Anáforas } & \multirow{10}{*}{$\begin{array}{c}\text { expressões } \\
\text { nominais } \\
\text { definidas }\end{array}$} & & \multicolumn{2}{|c|}{ SINTAGMA NOMINAL } & \multicolumn{4}{|c|}{ MODIFICADOR } \\
\hline & & & $\begin{array}{c}\text { determinante } \\
\text { (artigo } \\
\text { definido) }\end{array}$ & $\begin{array}{l}\text { nome- } \\
\text { núcleo }\end{array}$ & definições & descrições & oração adjetiva & \\
\hline & & \multirow{2}{*}{ metáforas } & as & vovós & do sexo & & & \\
\hline & & & as & damas & da noite & & & \\
\hline & & \multirow{6}{*}{ paráfrases } & as & profissionais & do sexo & $\begin{array}{l}\text { vitimas de uma } \\
\text { doença silenciosa. }\end{array}$ & & \\
\hline & & & as & prostitutas & & $\begin{array}{l}\text { vítimas de uma } \\
\text { doença silenciosa. }\end{array}$ & & \\
\hline & & & & mulheres & & $\begin{array}{l}\text { com mais de } 50 \\
\text { anos }\end{array}$ & $\begin{array}{l}\text { que se prostituem na zona } \\
\text { portuária de Santos. }\end{array}$ & \\
\hline & & & & mulheres & & & $\begin{array}{l}\text { que possuem mais de meio } \\
\text { século de vida. }\end{array}$ & \\
\hline & & & as & idosas & & & que ainda se prostituem. & \\
\hline & & & & Idosas & & & & se prostituem. \\
\hline
\end{tabular}

Quadro 1 - O processo de referenciação do objeto de discurso "prostituta idosa".

\section{REFERÊNCIAS}

BARBOSA, R. M. S. Garota de Programa: acontecimento discursivo(?) Dissertação/ Mestrado em Letras/UFMS (2008).

CARDOSO, Silvia H. B. A questão da referência: das teorias clássicas à dispersão de discursos. Campinas, SP: Autores Associados, 2003. 
CAVALCANTE, M.M. Anáfora e dêixis: quando as retas se encontram. In: KOCH, I. V.; MORATO, E. M.; BENTES, E. C. (Orgs.) Referenciação e discurso. São Paulo: Contexto, 2005.

CHARAUDEAU, Patrick. Discurso das mídias. São Paulo: Contexto, 2006.

KOCH, I.V. Referenciação e orientação argumentativa. In: KOCH, I.V. ; MORATO, E.M. BENTES, A. C. Referenciação e discurso. São Paulo-SP: Contexto, 2005. p.3352.

. Como se constroem e reconstroem os objetos-de-discurso. Investigações. v. 21, 2008, p. 99-114.

Contexto, 2009.

; ELIAS, Vanda. Ler e escrever: estratégias de produção textual. São Paulo:

MaINGUENEAU, D. Gênese dos discursos. Trad. S. Possenti. São Paulo: Parábola Editorial, 2004.

MARCUSCHI, Luiz Antônio. Anáfora indireta: o barco textual e suas âncoras. In: $\mathrm{KOCH}$, Ingedore Grunfeld Villaça; MORATO, Edwiges Maria; BENTES, Anna Christina. Referenciação e Discurso. São Paulo: Contexto, 2005. p. 53-101.

, L.A.; KOCH, I.V. Estratégias de referenciação e progressão referencial na língua falada. In: ABAURRE, M. B.; RODRIGUES, A.C.S. (Orgs.). Gramática do Português Falado. Campinas, SP: Ed. Da UNICAMP, 2002. V.8, Parte I.

REPÓRTER RECORD INVESTIGAÇÃO. 30-03-2015 Damas da Noite [Completo] Disponível em $<$ https://www.dailymotion.com/video/x2lm1b5 $>$. Acesso em jul. 2015.

ROBERTS, Nickie. Prostitutas na história. [Trad. Magda Lopes]. Rio de Janeiro: Record: Rosa dos Tempos, 1998.

Recebido em: agosto de 2017.

Aprovado em: outubro de 2017.

\section{Como citar este trabalho:}

BARBOSA, R. M. de S.; NASCIMENTO, C. A. G. de S. De damas da noite a vovós do sexo: referenciação da prostituta idosa na mídia. Traços de linguagem, v. 1, n. 2, p. 69-77, 2017. 